\title{
A Hybrid Electrode of $\mathrm{Co}_{3} \mathrm{O}_{4} @ P P y$ Core/Shell Nanosheet Arrays for High-Performance Supercapacitors
}

\author{
Xiaojun Yang ${ }^{1} \cdot$ Kaibing $\mathrm{Xu}^{1} \cdot$ Rujia Zou ${ }^{1} \cdot$ Junqing $\mathrm{Hu}^{1}$
}

Received: 17 August 2015/Accepted: 14 September 2015/Published online: 15 October 2015

(C) The Author(s) 2015. This article is published with open access at Springerlink.com

\begin{abstract}
Herein, combining solverthermal route and electrodeposition, we grew unique hybrid nanosheet arrays consisting of $\mathrm{Co}_{3} \mathrm{O}_{4}$ nanosheet as a core, PPy as a shell. Benefiting from the PPy as conducting polymer improving an electron transport rate as well as synergistic effects from such a core/shell structure, a hybrid electrode made of the $\mathrm{Co}_{3} \mathrm{O}_{4} @ \mathrm{PPy}$ core/shell nanosheet arrays exhibits a large areal capacitance of $2.11 \mathrm{~F} \mathrm{~cm}^{-2}$ at the current density of $2 \mathrm{~mA} \mathrm{~cm}^{-2}$, a 4fold enhancement compared with the pristine $\mathrm{Co}_{3} \mathrm{O}_{4}$ electrode; furthermore, this hybrid electrode also displays good rate capability $\left(\sim 65 \%\right.$ retention of the initial capacitance from 2 to $\left.20 \mathrm{~mA} \mathrm{~cm}{ }^{-2}\right)$ and superior cycling performance ( $\sim 85.5 \%$ capacitance retention after 5000 cycles). In addition, the equivalent series resistance value of the $\mathrm{Co}_{3} \mathrm{O}_{4} @ \mathrm{PPy}$ hybrid electrode $\left(0.238 \Omega\right.$ ) is significantly lower than that of the pristine $\mathrm{Co}_{3} \mathrm{O}_{4}$ electrode $(0.319 \Omega)$. These results imply that the $\mathrm{Co}_{3} \mathrm{O}_{4} @ P P y$ hybrid composites have a potential for fabricating next-generation energy storage and conversion devices.
\end{abstract}

Keywords $\quad \mathrm{Co}_{3} \mathrm{O}_{4} @ \mathrm{PPy} \cdot$ Core/shell nanosheet arrays $\cdot$ Supercapacitors

\section{Introduction}

With the rapid increasing demand in energy storage system for portable electronics and hybrid electric vehicles, supercapacitors have aroused widespread research interest owning to their high power density, fast charge-discharge rate and long lifespan [1-3]. As for a key component of the supercapacitors, electrode materials can be divided into

Electronic supplementary material The online version of this article (doi:10.1007/s40820-015-0069-x) contains supplementary material, which is available to authorized users.

Rujia Zou

rjzou@dhu.edu.cn

$\triangle$ Junqing $\mathrm{Hu}$

hu.junqing@dhu.edu.cn

1 State Key Laboratory for Modification of Chemical Fibers and Polymer Materials, College of Materials Science and Engineering, Donghua University, Shanghai 201620, People's Republic of China three major types: carbon materials $[4,5]$, transition metal oxides [6-8] and conducting polymers (CPs) $[9,10]$. Carbon materials store charges electrostatically through reversible ion adsorption at the electrode/electrolyte interface [11]. In comparison, transition metal oxides and CPs exploit the fast and reversible Faradic redox process at the electrode surface, thus delivering a considerably high specific capacitance $[12,13]$. Therefore, the electrode materials based on transition metal oxides and CPs are gradually becoming a research hotspot in the field of the supercapacitors [14-16].

Among various electrode materials, $\mathrm{Co}_{3} \mathrm{O}_{4}$ is one of the most extensively investigated pseudocapacitive materials because of its low cost, environmental friendliness and high theoretical capacitance $\left(\sim 3560 \mathrm{~F} \mathrm{~g}^{-1}\right)$ [8]. Importantly, it can provide multiple oxide states for reversible redox process [17]. Despite these appealing features, the real specific capacitance obtained from various $\mathrm{Co}_{3} \mathrm{O}_{4}$ nanostructures [18-20] is still far below the theoretical value, which may be attributed to its intrinsic semiconducting characteristic [21]. To overcome this problem, one effective method is 
fabricating addictive/binder-free electrode configuration to avoid the "dead surface" and tedious process in traditional slurry-coating electrode. $\mathrm{Ni}$ foam is widely used as the substrate to support metal oxides materials because of its good electrical conductivity and porous structure, which can enhance the electron transport and improve the active site of electrode materials. Simultaneously, another feasible method is designing three-dimensional (3D) hybrid electrode with large surface area and fast electron transport. Recently, integrating carbon materials, CPs, or noble metal nanoparticles onto electroactive materials has been demonstrated to be an effective synthesis route. Wang et al. [22] successfully prepared $\mathrm{Co}_{3} \mathrm{O}_{4} @$ MWCNTs hybrid composites, which show superior electrochemical performance as positive electrode materials. As one of the most important CPs, polypyrrole (PPy) has been a promising pseudocapacitive electrode material because of its low cost, good electrical conductivity, relatively high capacitance, and outstanding mechanical flexibility [23]. For instance, Liu et al. [24] fabricated a supercapacitor electrode composed of CoO@PPy hybrid nanowires, which delivers a remarkably large areal capacitance of $4.43 \mathrm{~F} \mathrm{~cm}^{-2}$ at $1 \mathrm{~mA} \mathrm{~cm}{ }^{-2}$, excellent rate capability and cycling performance; Hong et al. [25] developed a $\mathrm{Co}_{3} \mathrm{O}_{4} @ \mathrm{Au}-\mathrm{PPy}$ core/ shell nanowires electrode, which exhibits a high specific capacitance of $2062 \mathrm{~F} \mathrm{~g}^{-1}\left(6.39 \mathrm{~F} \mathrm{~cm}^{-2}\right)$ at $5 \mathrm{~mA} \mathrm{~cm}{ }^{-2}$, with $\sim 68 \%$ retention of the initial capacitance from 5 to $50 \mathrm{~mA} \mathrm{~cm}{ }^{-2}$. However, Au as a noble metal is quite costly, and the in situ interfacial polymerization process is timeconsuming. In contrast, electrodeposition technique has great advantages, such as convenient, low cost, controllable, and efficient. Thus, it is of great interest to develop a low cost and efficient route to fabricate 3D $\mathrm{Co}_{3} \mathrm{O}_{4} @ \mathrm{PPy}$ hybrid electrode with enhanced electrical conductivity and excellent electrochemical performance for supercapacitor applications.

Based on above consideration, we designed a 3D core/ shell nanostructure of uniform PPy thin layer on mesoporous $\mathrm{Co}_{3} \mathrm{O}_{4}$ nanosheet arrays as a hybrid electrode material through a solvothermal and electrodeposition process. A hybrid electrode made of as-grown $\mathrm{Co}_{3} \mathrm{O}_{4} @ \mathrm{PPy}$ core/shell nanosheet arrays exhibits a large areal capacitance of $2.11 \mathrm{~F} \mathrm{~cm}^{-2}$ at the current density of $2 \mathrm{~mA} \mathrm{~cm}^{-2}$, which is superior to $0.54 \mathrm{~F} \mathrm{~cm}^{-2}$ of the pristine $\mathrm{Co}_{3} \mathrm{O}_{4}$ electrode. Meanwhile, this electrode also displays a good rate capability $\left(1.37 \mathrm{~F} \mathrm{~cm}^{-2}\right.$ at the current density of $20 \mathrm{~mA} \mathrm{~cm}{ }^{-2}$ ). Most importantly, the $\mathrm{Co}_{3} \mathrm{O}_{4} @$ PPy hybrid electrode demonstrates a superior cycling performance ( $\sim 85.5 \%$ capacitance retention after 5000 cycles). Furthermore, the equivalent series resistance (ESR) value of the $\mathrm{Co}_{3} \mathrm{O}_{4} @$ PPy hybrid electrode $(0.238 \Omega)$ is significantly lower than that of the pristine $\mathrm{Co}_{3} \mathrm{O}_{4}$ electrode $(0.319 \Omega)$, indicting the enhanced electrical conductivtity.

\section{Experimental}

\subsection{Synthesis of Mesoporous $\mathrm{Co}_{3} \mathrm{O}_{4}$ Nanosheet Arrays}

All reagents used in the work were of analytical grade. A hybrid electrode configuration was prepared by a facile two-step method, which can be easily scaled up. Typically, a piece of $\mathrm{Ni}$ foam (ca. $4 \times 1 \mathrm{~cm}^{2}$ ) was carefully pretreated with $3 \mathrm{M} \mathrm{HCl}$ aqueous by ultrasonication for $30 \mathrm{~min}$, and then cleaned with deionized water and absolute ethanol for several times. $2 \mathrm{mmol}$ of $\mathrm{Co}\left(\mathrm{NO}_{3}\right)_{2} \cdot 6 \mathrm{H}_{2} \mathrm{O}$ and $5 \mathrm{mmol}$ of hexamethylenetetramine (HMT) were dissolved in $25 \mathrm{~mL}$ of deionized water and $25 \mathrm{~mL}$ of absolute ethanol under magnetic stirring for $30 \mathrm{~min}$. Then, the resulting solution was transferred into a $60 \mathrm{~mL}$ Teflonlined autoclave and a piece of cleaned $\mathrm{Ni}$ foam substrate was immersed into it. Subsequently, the autoclave was sealed and maintained in an electric oven at $90{ }^{\circ} \mathrm{C}$ for $8 \mathrm{~h}$. After cooling down to room temperature naturally, the products were rinsed with deionized water and absolute ethanol for several times, and then dried at $60^{\circ} \mathrm{C}$ for $2 \mathrm{~h}$. Finally, the as-prepared samples were calcined at $300{ }^{\circ} \mathrm{C}$ in air for $2 \mathrm{~h}$.

\subsection{Synthesis of $\mathrm{Co}_{3} \mathrm{O}_{4} @ P P y$ Core/Shell Nanosheet Arrays}

PPy thin layer was grown on the surface of mesoporous $\mathrm{Co}_{3} \mathrm{O}_{4}$ nanosheet arrays by electrodeposition. The procedure of eletrodeposition was accomplished in a threeelectrode system by using the $\mathrm{Ni}$ foam-supported as-grown $\mathrm{Co}_{3} \mathrm{O}_{4}$ electrode materials as the working electrode, a $\mathrm{Pt}$ foil as the counter electrode, and $\mathrm{Ag} / \mathrm{AgCl}$ as the reference electrode. Electrolyte for electrodeposition of PPy was prepared by dissolving $0.4 \mathrm{~mL}$ of pyrrole $(288 \mathrm{mM})$ and $0.1491 \mathrm{~g}$ of $\mathrm{KCl}(100 \mathrm{mM})$ into $20 \mathrm{~mL}$ of deionized water. Then, the $\mathrm{Co}_{3} \mathrm{O}_{4} @ \mathrm{PPy}$ core/shell nanosheet arrays were synthesized at $0.8 \mathrm{~V}$ for a different duration of $2,5,8$, and 10 min. Finally, as-prepared $\mathrm{Co}_{3} \mathrm{O}_{4} @ P P y$ hybrid electrode materials were rinsed with deionized water and absolute ethanol for several times, and then dried at $60{ }^{\circ} \mathrm{C}$ for $2 \mathrm{~h}$.

\subsection{Structure Characterization}

As-synthesized products were characterized by D/Max-2550 PC X-ray diffractometer (XRD, Rigaku, $\mathrm{Cu}-\mathrm{K} \alpha$ radiation), X-ray photoelectron spectroscopy (XPS, PHI5000VersaProbe), scanning electron microscopy (SEM, HITACHI, S-4800) and transmission electron microscopy (TEM, JEOL, JEM-2100F) equipped with an energy-dispersive X-ray spectrometer (EDX). The $\mathrm{Co}_{3} \mathrm{O}_{4} @ \mathrm{PPy}$ samples were easily 
scraped off from the Ni foam substrate for the Fourier transform infrared (FTIR) test, and the FTIR spectrum was recorded on a Nicolet 6700 FTIR spectrometer (Bruker).

\subsection{Electrochemical Characterization}

Electrochemical measurements were performed on an Autolab electrochemical workstation (PGSTAT302N) using a three-electrode system and $1 \mathrm{M} \mathrm{KOH}$ as the electrolyte. A Pt foil and a saturated calomel electrode (SCE) were used as the counter electrode and the reference electrode, respectively. The Ni foam-supported $\mathrm{Co}_{3} \mathrm{O}_{4} @$ PPy and $\mathrm{Co}_{3} \mathrm{O}_{4}$ electrode materials (ca. $1 \mathrm{~cm}^{2}$ area) acted directly as the working electrode.

\section{Results and Discussion}

In this study, the $\mathrm{Co}_{3} \mathrm{O}_{4} @ \mathrm{PPy}$ hybrid nanosheet arrays were synthesized through a solvothermal and electrodeposition process. The synthesis procedure of the hybrid nanosheet arrays is briefly summarized in the accessible two steps as shown in Fig. 1. Firstly, mesoporous $\mathrm{Co}_{3} \mathrm{O}_{4}$ nanosheet arrays were grown vertically on the $\mathrm{Ni}$ foam via a solvothermal and calcination procedure. The 3D Ni foam has been widely employed as an ideal current collector owning to its uniform macropores, large supporting area (Fig. S1), and high electrical conductivity [26]. Secondly, PPy was continually integrated onto the surface of the mesoporous $\mathrm{Co}_{3} \mathrm{O}_{4}$ nanosheet arrays via a controllable and efficient electrodeposition technique. The detailed synthesis procedure of $\mathrm{Co}_{3} \mathrm{O}_{4} @$ PPy hybrid nanosheet arrays was described in the Experimental section. In our design, the PPy shell not only enhances the electrical conductivity of the overall electrode that can facilitate electronic and ion diffusion and improve the utilization of electrode materials, but also contributes to the total capacitance owning to its synergistic effects. We envisage that such a unique hybrid nanostructured electrode together with abovementioned merits will display excellent electrochemical performance in charge storage.

Different magnification scanning electron microscopy (SEM) images of the pristine $\mathrm{Co}_{3} \mathrm{O}_{4}$ nanosheets are shown in Fig. 2a-c, respectively. A low-magnification SEM image (Fig. 2a) shows that the $\mathrm{Co}_{3} \mathrm{O}_{4}$ nanosheets are densely and uniformly grown on each strip of the Ni foam. As observed in higher-magnification SEM images (Fig. 2b, c), the $\mathrm{Co}_{3} \mathrm{O}_{4}$ nanosheets are interconnected with each other and approximately perpendicular to the $\mathrm{Ni}$ foam, forming a highly porous structure with broad open space. A TEM image (Fig. 2d) verifies that numerous mesopores are uniformly distributed throughout the overall surface of an individual $\mathrm{Co}_{3} \mathrm{O}_{4}$ nanosheet, and the porous size ranges from 2 to $10 \mathrm{~nm}$, suggesting its mostly ultrathin feature. The formation of the mesopores could be related to the removal of water molecules during oxidative transformation of precursor to $\mathrm{Co}_{3} \mathrm{O}_{4}$ [27]. Such an electrode material with nearly vertical nanosheet arrays and highly porous structure can provide abundant electroactive sites, which is beneficial to charge transport and ion diffusion without the necessity of binder blocks, thereby resulting in improved charge transfer kinetics. A high-resolution TEM (HRTEM) image shown in Fig. 2e demonstrates that as-synthesized $\mathrm{Co}_{3} \mathrm{O}_{4}$ nanosheets give lattice fringes with interplanar spacings of 0.286 and $0.244 \mathrm{~nm}$, corresponding to the (220) and (311) plane of the cubic $\mathrm{Co}_{3} \mathrm{O}_{4}$, respectively. The XRD pattern in Fig. 2f reveals the crystal structure and phase purity of as-synthesized $\mathrm{Co}_{3} \mathrm{O}_{4}$ nanosheets. All the diffraction peaks can be indexed into a pure face-centered cubic phase $\mathrm{Co}_{3} \mathrm{O}_{4}$ with a lattice constant of $a=8.08 \AA$ (JCPDS Card No. 42-1467).

The interconnected mesoporous $\mathrm{Co}_{3} \mathrm{O}_{4}$ nanosheet arrays can serve as an effective scaffold for loading additional electroactive pseudocapacitive electrode materials. In order to further enhance the electrochemical performance, PPy was chosen as an appropriate coating deposited on the mesoporous $\mathrm{Co}_{3} \mathrm{O}_{4}$ nanosheet arrays. The morphology and structure of the $\mathrm{Co}_{3} \mathrm{O}_{4} @$ PPy hybrid composites were characterized by SEM and TEM. As shown in Fig. 3a, b, wrinkle-like PPy thin layer densely covers the surface of the $\mathrm{Co}_{3} \mathrm{O}_{4}$ nanosheets. Notably, the decoration of the PPy coating significantly increases the thickness and surface roughness of the $\mathrm{Co}_{3} \mathrm{O}_{4}$ nanosheets, whereas the $\mathrm{Co}_{3}$ $\mathrm{O}_{4} @$ PPy hybrid composites well maintain the ordered nanostructure. The TEM image in Fig. 3c clearly illustrates that partial porous structure has been covered by the PPy coating, as compared with the pristine $\mathrm{Co}_{3} \mathrm{O}_{4}$ nanosheets. Moreover, XPS measurement was employed to prove the

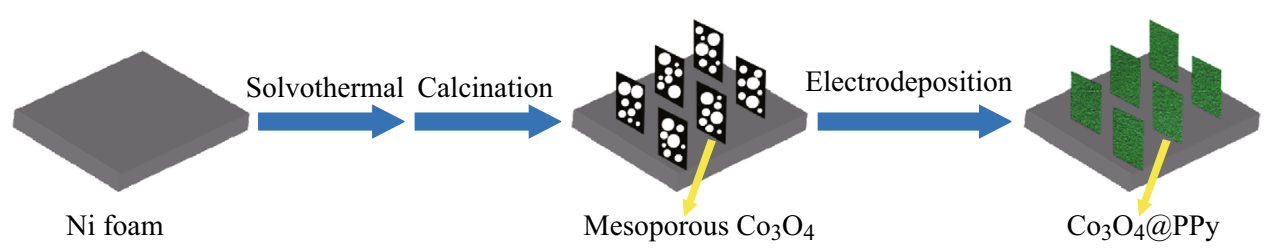

Fig. 1 Schematic diagram for the synthesis of mesoporous $\mathrm{Co}_{3} \mathrm{O}_{4} @ \mathrm{PPy}$ hybrid nanosheet arrays on Ni foam 

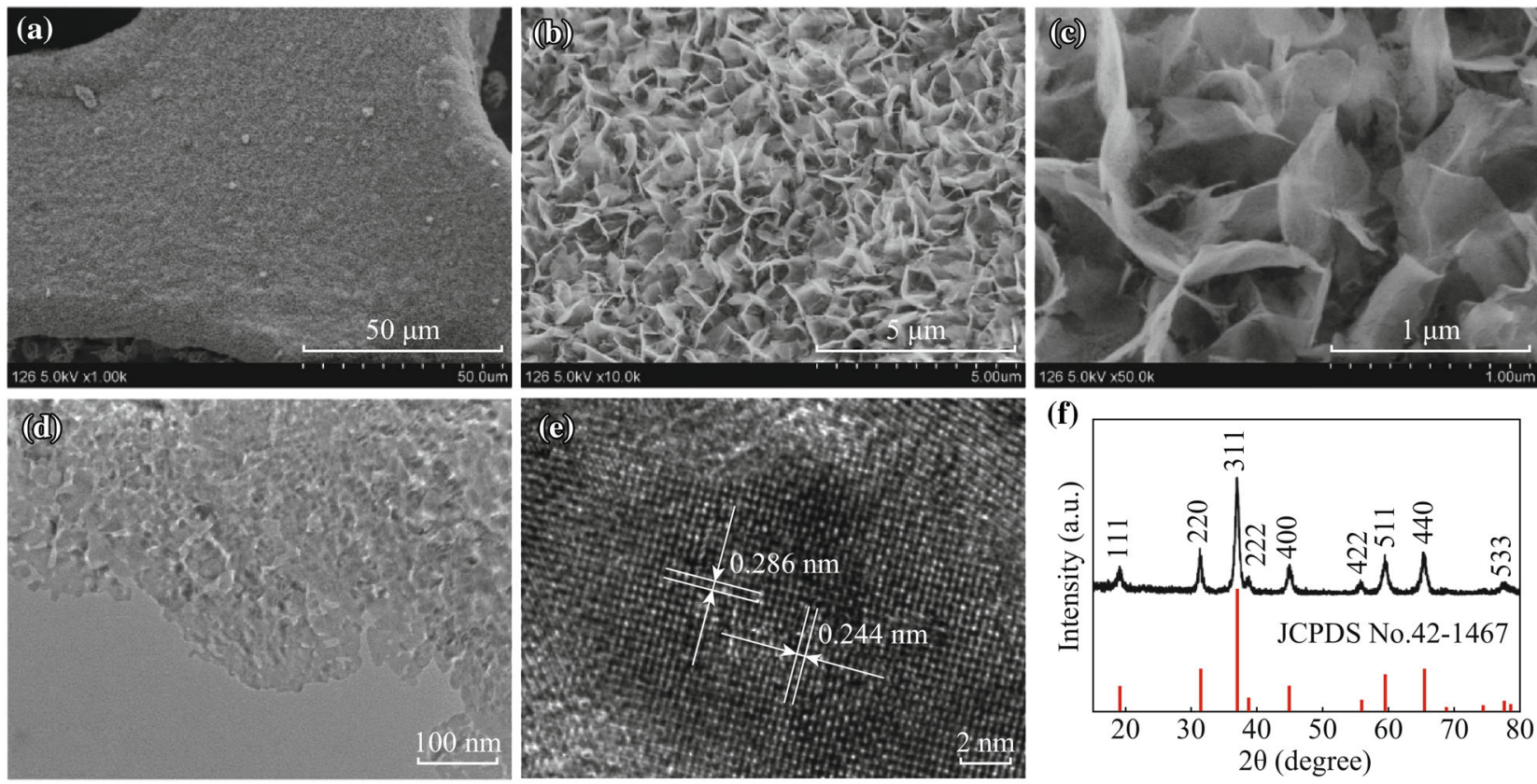

Fig. 2 a-c Different magnification SEM images of the mesoporous $\mathrm{Co}_{3} \mathrm{O}_{4}$ nanosheet arrays on Ni foam. d, e TEM and HRTEM images of the $\mathrm{Co}_{3} \mathrm{O}_{4}$ nanosheets. $f$ XRD pattern of the $\mathrm{Co}_{3} \mathrm{O}_{4}$ nanosheets scraped off from the $\mathrm{Ni}$ foam
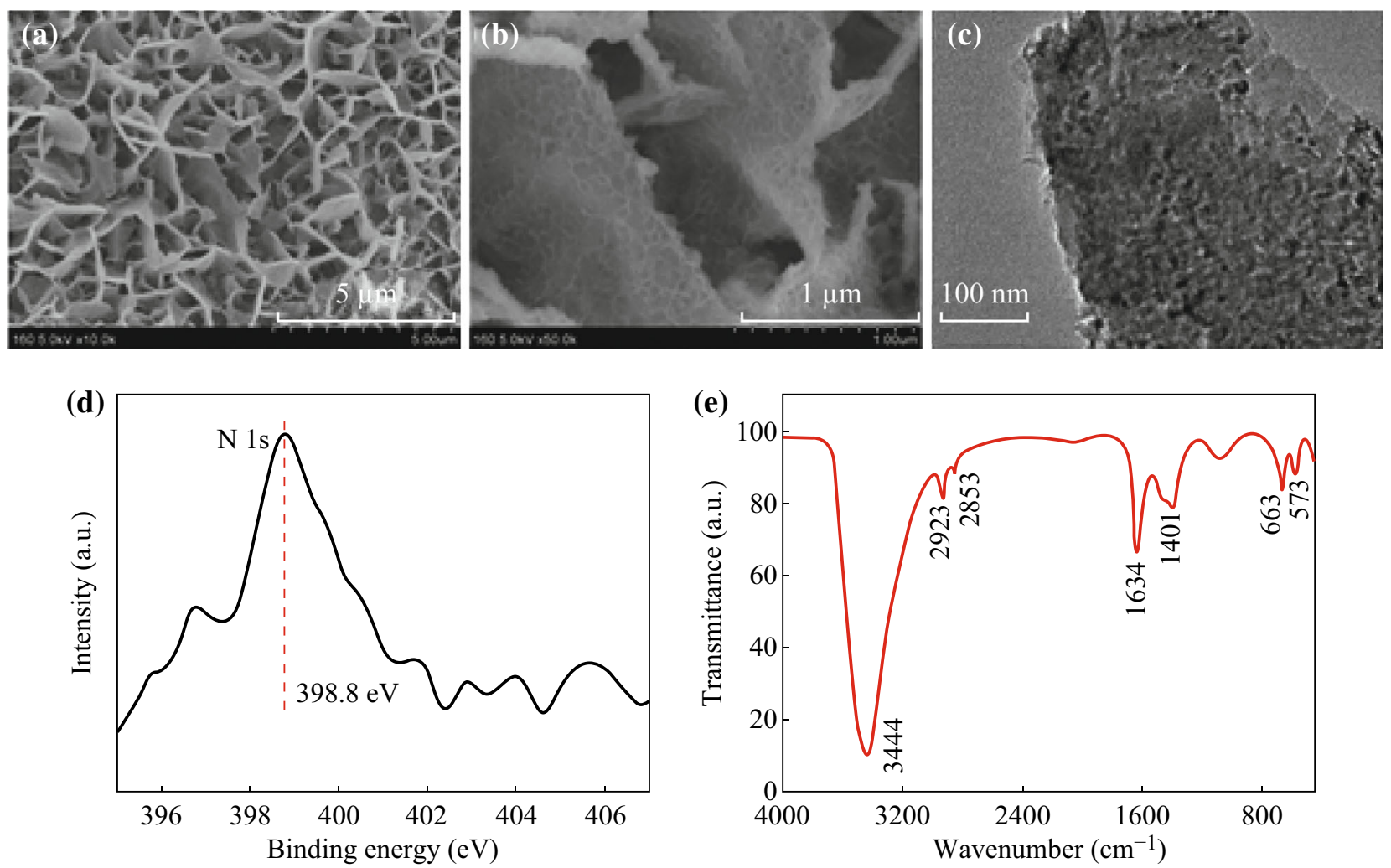

Fig. 3 a-c SEM and TEM images of the $\mathrm{Co}_{3} \mathrm{O}_{4} @$ ppy hybrid composites after 5 min electrodeposition. d XPS spectrum of $\mathrm{N} 1 \mathrm{~s}$ for the $\mathrm{Co}_{3} \mathrm{O}_{4} @$ ppy hybrid composites. e FTIR adsorption spectrum of the $\mathrm{Co}_{3} \mathrm{O}_{4} @$ ppy hybrid composites 
existence of the PPy coating. The binding energy of $\mathrm{N} 1 \mathrm{~s}$ peak (Fig. 3d) is centered at $398.8 \mathrm{eV}$, which corresponds to the neutral nitrogen moieties $(-\mathrm{NH}-)$ on PPy $[28,29]$. Figure $3 \mathrm{e}$ shows the FTIR adsorption spectrum of the $\mathrm{Co}_{3} \mathrm{O}_{4} @$ PPy hybrid composites. A strong adsorption peak at $3444 \mathrm{~cm}^{-1}$ should be the stretching vibration of $\mathrm{N}-\mathrm{H}$. Two peaks at 1634 and $1401 \mathrm{~cm}^{-1}$ are induced by $\mathrm{C}=\mathrm{C}$ and $\mathrm{C}-\mathrm{N}$ on the pyrrole ring, respectively [30]. The peaks at 2923 and $2853 \mathrm{~cm}^{-1}$ are designated as the asymmetric stretching and symmetric vibrations of $\mathrm{CH}_{2}$ [31]. Other obvious peaks at 663 and $573 \mathrm{~cm}^{-1}$ are attributed to $\mathrm{Co}-\mathrm{O}$ stretching in $\mathrm{Co}_{3} \mathrm{O}_{4}$ [32]. According to abovementioned characterizations, we convince that the $\mathrm{Co}_{3} \mathrm{O}_{4} @$ PPy hybrid composites have been successfully synthesized.

To evaluate the electrochemical performance of the $\mathrm{Co}_{3} \mathrm{O}_{4} @$ PPy hybrid electrode using the $\mathrm{Co}_{3} \mathrm{O}_{4}$ electrode as a comparison, electrochemical measurements were conducted in a three-electrode cell with a Pt counter electrode and a
SCE reference electrode in $1 \mathrm{M} \mathrm{KOH}$ electrolyte. Figure $4 \mathrm{a}$ shows the cyclic voltammetry $(\mathrm{CV})$ curves of the $\mathrm{Co}_{3-}$ $\mathrm{O}_{4} @$ PPy hybrid electrode and $\mathrm{Co}_{3} \mathrm{O}_{4}$ electrode at a scan rate of $50 \mathrm{mV} \mathrm{s}^{-1}$ with the potential range of 0 to $0.55 \mathrm{~V}$. It is particularly noteworthy that after coating a PPy thin layer, the enclosed CV curve of the $\mathrm{Co}_{3} \mathrm{O}_{4} @$ PPy hybrid electrode expands drastically, indicating that much larger capacitance is obtained owning to their synergistic effects from two materials of $\mathrm{Co}_{3} \mathrm{O}_{4}$ and PPy. Firstly, PPy can provide good electrical conductivity, which will definitely result in improved electron transport rate through individual nanosheets. Secondly, PPy itself behaves additional pseudocapacitance during ion doping/dedoping in alkaline solution [24]. Figure $4 \mathrm{~b}$ displays the $\mathrm{CV}$ curves of the $\mathrm{Co}_{3} \mathrm{O}_{4} @$ PPy hybrid electrode at various scan rates. The profile of these curves is not significantly changed with an increasing scan rate from 2 to $80 \mathrm{mV} \mathrm{s}^{-1}$, indicating a reversible electrochemical process and an ideal
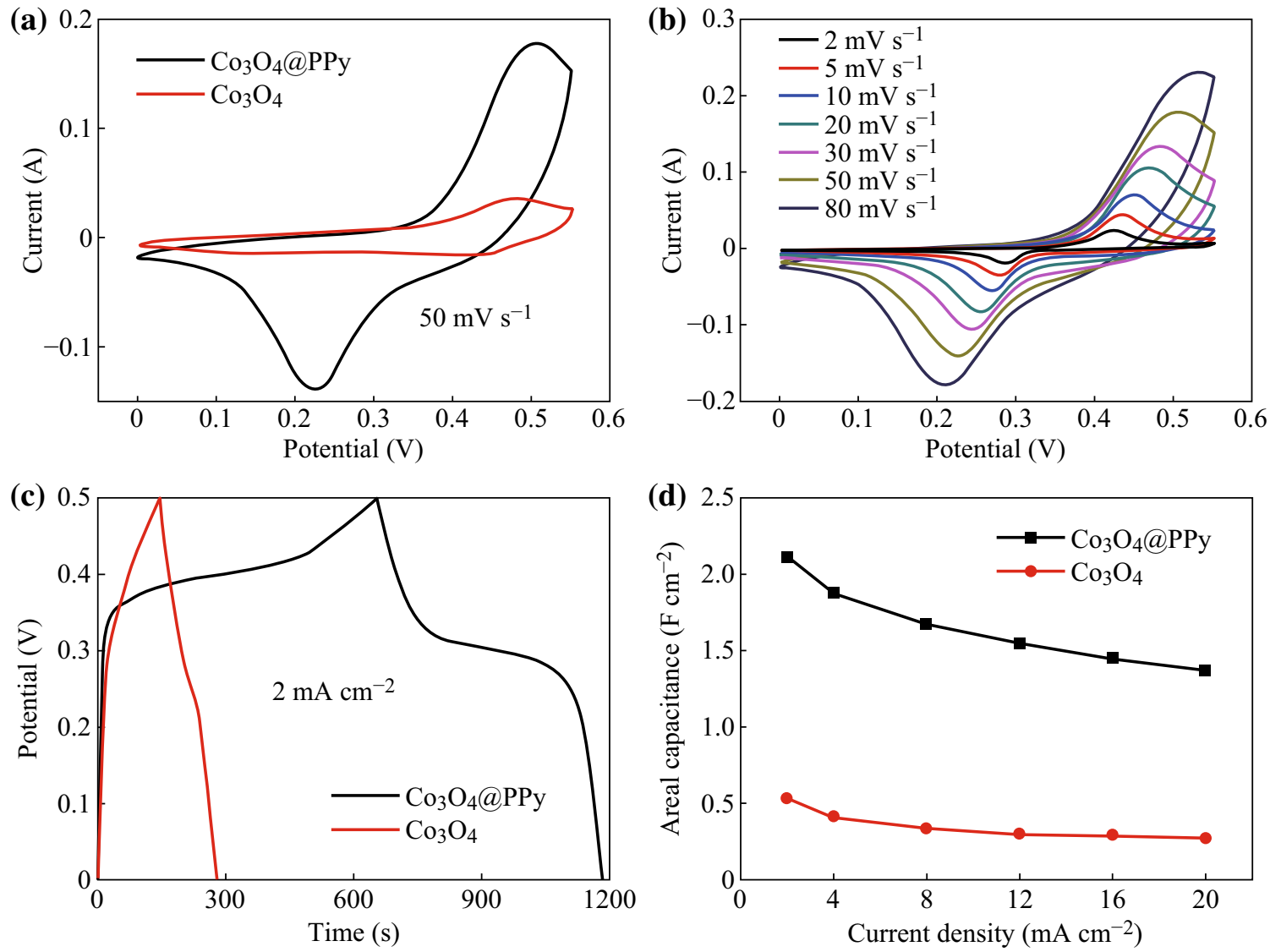

Fig. 4 a CV curves of the $\mathrm{Co}_{3} \mathrm{O}_{4} @$ ppy hybrid electrode and $\mathrm{Co}_{3} \mathrm{O}_{4}$ electrode at a scan rate of $50 \mathrm{mV} \mathrm{s}{ }^{-1}$. b CV curves of the Co $3 \mathrm{O}_{4} @$ ppy hybrid electrode and $\mathrm{Co}_{3} \mathrm{O}_{4}$ electrode at various scan rates. $\mathbf{c} \mathrm{CD}$ curves of the $\mathrm{Co}_{3} \mathrm{O}_{4} @$ ppy hybrid electrode and $\mathrm{Co}_{3} \mathrm{O}_{4}$ electrode with a current density of $2 \mathrm{~mA} \mathrm{~cm}^{-2}$. d Areal capacitances of the $\mathrm{Co}_{3} \mathrm{O}_{4} @$ ppy hybrid electrode and $\mathrm{Co}_{3} \mathrm{O}_{4}$ electrode at various current densities 
pseudocapacitive characteristic. In addition, the redox peaks slowly move toward positive/negative potential along with the increasing of scan rate, revealing a good contact between the electroactive $\mathrm{Co}_{3} \mathrm{O}_{4} @$ PPy nanosheets and the conductive Ni foam substrate. Figure $4 \mathrm{c}$ shows the galvanostatic charge-discharge (CD) curves of the $\mathrm{Co}_{3} \mathrm{O}_{4} @$ PPy hybrid electrode and $\mathrm{Co}_{3} \mathrm{O}_{4}$ electrode at the current density of $2 \mathrm{~mA} \mathrm{~cm}{ }^{-2}$. As expected, the $\mathrm{Co}_{3} \mathrm{O}_{4} @$ PPy hybrid electrode displays much longer discharging time than the pristine $\mathrm{Co}_{3} \mathrm{O}_{4}$ electrode. It denotes that the $\mathrm{Co}_{3} \mathrm{O}_{4} @$ PPy hybrid electrode exhibit much larger areal capacitance than the pristine $\mathrm{Co}_{3} \mathrm{O}_{4}$ electrode, corresponding to the $\mathrm{CV}$ test. The areal capacitances of the $\mathrm{Co}_{3} \mathrm{O}_{4} @ P P y$ hybrid electrode and $\mathrm{Co}_{3} \mathrm{O}_{4}$ electrode are calculated based on the discharge curves (Fig. S2) measured at various current densities via the following formula [33]: $C=I \Delta t / S \Delta V$, where $I$ (A) is the discharge current, $\Delta t(\mathrm{~s})$ is the discharge time, $S$ is the geometric area of the active electrode, and $\Delta V(\mathrm{~V})$ is the voltage interval, as illustrated in Fig. 4d. Correspondingly, the areal capacitances of the $\mathrm{Co}_{3} \mathrm{O}_{4} @$ PPy hybrid electrode with different electrodeposition times are examined and plotted in Fig. S3. The $\mathrm{Co}_{3} \mathrm{O}_{4} @$ PPy hybrid electrode after $8 \mathrm{~min}$ electrodeposition delivers the largest areal capacitance of $2.11 \mathrm{~F} \mathrm{~cm}^{-2}$ at the current density of $2 \mathrm{~mA} \mathrm{~cm}^{-2}$, which is remarkably larger than the value obtained for the pristine $\mathrm{Co}_{3} \mathrm{O}_{4}$ electrode $\left(0.54 \mathrm{~F} \mathrm{~cm}^{-2}\right)$. The $\mathrm{Co}_{3} \mathrm{O}_{4} @$ PPy hybrid electrode still has an areal capacitance of $1.37 \mathrm{~F} \mathrm{~cm}^{-2}$ when the current density is increased to $20 \mathrm{~mA} \mathrm{~cm}{ }^{-2}$, demonstrating its outstanding rate capability $(\sim 65 \%)$. For comparison, the capacity retention of the pristine $\mathrm{Co}_{3} \mathrm{O}_{4}$ electrode is only $\sim 50 \%$ at the current density of $20 \mathrm{~mA} \mathrm{~cm}^{-2}$. To our best knowledge, the excellent electrochemical performance of the $\mathrm{Co}_{3} \mathrm{O}_{4} @ P P y$ hybrid electrode presented here is superior to those of previously reported electrodes (see Table 1). Such a large areal capacitance of the as-synthesized $\mathrm{Co}_{3} \mathrm{O}_{4} @ \mathrm{PPy}$ hybrid electrode will demonstrate a great advantage in improving the energy density of supercapacitors.

Cycling performance is another key factor for supercapacitor applications. Herein, a long-term cycling performance of the as-synthesized electrode materials was examined and compared at a scan rate of $50 \mathrm{mV} \mathrm{s}^{-1}$ for 5000 cycles, as shown in Fig. 5a. The overall capacitance retention of the $\mathrm{Co}_{3} \mathrm{O}_{4} @ \mathrm{PPy}$ hybrid electrode can reach $\sim 85.5 \%$ after 5000 cycles, indicting a superior cycling performance [38-41]; as a comparison, the overall capacitance retention of the pristine $\mathrm{Co}_{3} \mathrm{O}_{4}$ electrode is $97.7 \%$, suggesting that the $\mathrm{Co}_{3} \mathrm{O}_{4} @ \mathrm{PPy}$ hybrid electrode has a $\sim 12 \%$ decrease of the capacitance retention. As is known to all, PPy intrinsically exhibits poor cycling performance caused by its large volumetric swelling and shrinking during ion doping/dedoping process [42]. Therefore, it is not difficult to understand the declining of cycling performance after coating the PPy thin layer. In order to further investigate the electrochemical performance of the assynthesized electrode materials, electrochemical impedance spectroscopy (EIS) measurement was also conducted to evaluate the electrical conductivity and ion diffusion. As shown in Fig. 5b, the Nyquist plots at higher frequency deliver the ESR value of the $\mathrm{Co}_{3} \mathrm{O}_{4} @$ PPy hybrid electrode $(0.238 \Omega)$ and the pristine $\mathrm{Co}_{3} \mathrm{O}_{4}$ electrode $(0.319 \Omega)$, indicating the enhanced electrical conductivity after coating the PPy thin layer [43]. The EIS results imply the easy penetration of the electrolyte into the hybrid electrode and the improved utilization rate of the electrode materials, which can well explain the significantly enhanced areal capacitance as discussed above.

\section{Conclusion}

In summary, a hybrid nanomaterial of $\mathrm{Co}_{3} \mathrm{O}_{4} @ \mathrm{PPy}$ core/ shell nanosheet arrays on $\mathrm{Ni}$ foam was prepared through a solvothermal and electrodeposition process. The $\mathrm{Co}_{3} \mathrm{O}_{4} @$ PPy hybrid electrode exhibits a large areal capacitance of $2.11 \mathrm{~F} \mathrm{~cm}^{-2}$ at the current density of $2 \mathrm{~mA} \mathrm{~cm}^{-2}, \mathrm{a} \sim 4$ fold enhancement compared with the pristine $\mathrm{Co}_{3} \mathrm{O}_{4}$ electrode. Furthermore, the $\mathrm{Co}_{3} \mathrm{O}_{4} @ \mathrm{PPy}$ hybrid electrode also displays good rate capability ( $\sim 65 \%$ retention of the initial capacitance from 2 to $20 \mathrm{~mA} \mathrm{~cm}{ }^{-2}$ ) and superior cycling performance $(\sim 85.5 \%$ capacitance retention after 5000 cycles). In addition, the ESR value of the $\mathrm{Co}_{3} \mathrm{O}_{4} @ P P y$
Table 1 Comparison of performance metrics for the $\mathrm{Co}_{3} \mathrm{O}_{4} @$ PPy electrode materials with several reported electrode materials in previous literatures

\begin{tabular}{|c|c|c|}
\hline Electrode materials & Areal capacitance & Refs. \\
\hline $\mathrm{Co}_{3} \mathrm{O}_{4} @ \mathrm{PPy}$ hybrid composites & $2.11 \mathrm{~F} \mathrm{~cm}^{-2}$ at $2 \mathrm{~mA} \mathrm{~cm}^{-2}$ & This work \\
\hline Mesoporous $\mathrm{Co}_{3} \mathrm{O}_{4}$ nanosheets & $0.54 \mathrm{~F} \mathrm{~cm}^{-2}$ at $2 \mathrm{~mA} \mathrm{~cm}^{-2}$ & This work \\
\hline $\mathrm{Co}_{3} \mathrm{O}_{4} @ \mathrm{PPy} @ \mathrm{MnO}_{2}$ core/shell/shell nanowires & $1.13 \mathrm{~F} \mathrm{~cm}^{-2}$ at $1.2 \mathrm{~mA} \mathrm{~cm}^{-2}$ & {$[34]$} \\
\hline $\mathrm{Co}_{3} \mathrm{O}_{4} @ \mathrm{PPy} @ \mathrm{MnO}_{2}$ ternary core/shell composites & $0.55 \mathrm{~F} \mathrm{~cm}^{-2}$ at $0.5 \mathrm{~A} \mathrm{~g}^{-1}$ & [35] \\
\hline $\mathrm{Co}_{3} \mathrm{O}_{4} @ \mathrm{MnO}_{2}$ core/shell nanowires & $0.56 \mathrm{~F} \mathrm{~cm}^{-2}$ at $11.25 \mathrm{~mA} \mathrm{~cm}^{-2}$ & [6] \\
\hline $\mathrm{Co}_{3} \mathrm{O}_{4} @ \mathrm{NiO}$ core/shell nanowires & $1.35 \mathrm{~F} \mathrm{~cm}^{-2}$ at $6 \mathrm{~mA} \mathrm{~cm}{ }^{-2}$ & [12] \\
\hline 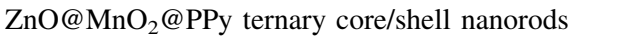 & $1.793 \mathrm{~F} \mathrm{~cm}^{-2}$ at $2 \mathrm{~A} \mathrm{~g}^{-1}$ & [36] \\
\hline FEG/PPy hybrid composites & $0.56 \mathrm{~F} \mathrm{~cm}^{-2}$ at $1 \mathrm{~mA} \mathrm{~cm}{ }^{-2}$ & [37] \\
\hline
\end{tabular}



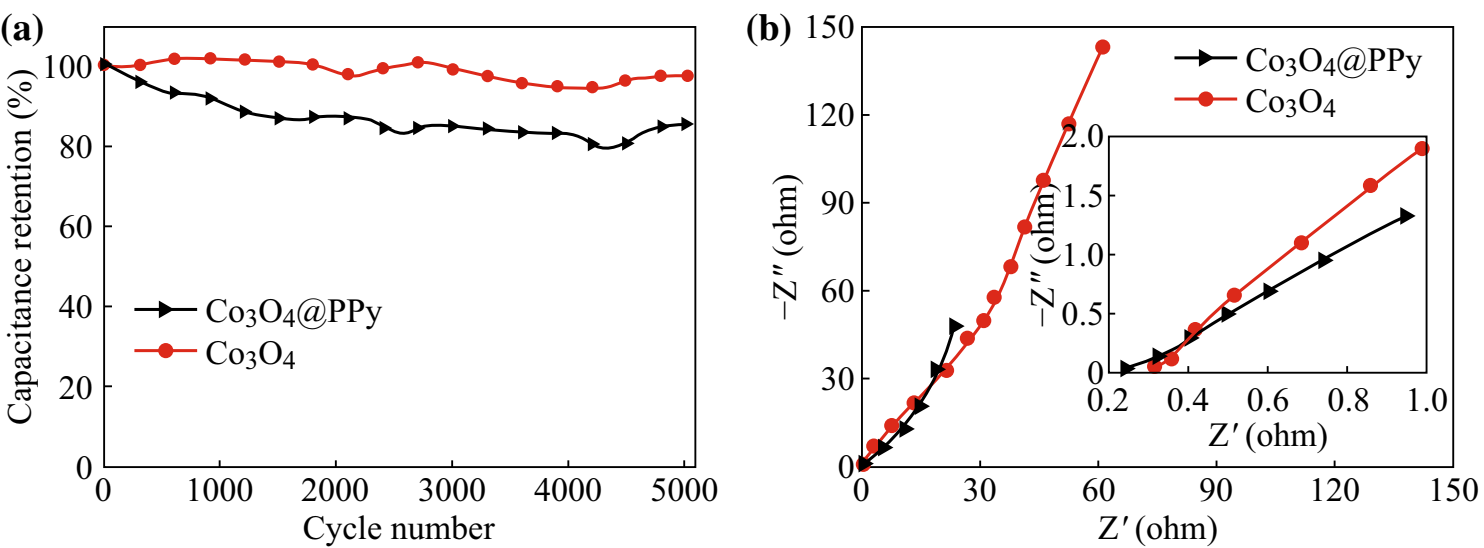

Fig. 5 a Cycling performance of the $\mathrm{Co}_{3} \mathrm{O}_{4} @$ ppy hybrid electrode and $\mathrm{Co}_{3} \mathrm{O}_{4}$ electrode tested at a scan rate of $50 \mathrm{mV} \mathrm{s}^{-1}$ for 5000 cycles. b Compared EIS curves of the $\mathrm{Co}_{3} \mathrm{O}_{4} @$ ppy hybrid electrode and $\mathrm{Co}_{3} \mathrm{O}_{4}$ electrode. The inset delivers the enlarged nyquist plots at higher frequency

hybrid electrode $(0.238 \Omega)$ is significantly lower than that of the pristine $\mathrm{Co}_{3} \mathrm{O}_{4}$ electrode $(0.319 \Omega)$. The outstanding electrochemical performance can enable the $\mathrm{Co}_{3} \mathrm{O}_{4} @ \mathrm{PPy}$ hybrid composites to be a promising electrode material for next-generation energy storage and conversion devices.

Acknowledgments This work was financially supported by the National Natural Science Foundation of China (Grant No. 21171035, 51472049 and 51302035), the Key Grant Project of Chinese Ministry of Education (Grant No. 313015), the PhD Programs Foundation of the Ministry of Education of China (Grant No. 20110075110008 and 20130075120001), the National 863 Program of China (Grant No. 2013AA031903), the Science and Technology Commission of Shanghai Municipality (Grant No. 13ZR1451200), the Fundamental Research Funds for the Central Universities, the Program Innovative Research Team in University (IRT1221), the Shanghai Leading Academic Discipline Project (Grant No. B603), and the Program of Introducing Talents of Discipline to Universities (No. 111-2-04).

Open Access This article is distributed under the terms of the Creative Commons Attribution 4.0 International License (http://crea tivecommons.org/licenses/by/4.0/), which permits unrestricted use, distribution, and reproduction in any medium, provided you give appropriate credit to the original author(s) and the source, provide a link to the Creative Commons license, and indicate if changes were made.

\section{References}

1. P. Simon, Y. Gogotsi, Materials for electrochemical capacitors. Nat. Mater. 7(11), 845-854 (2008). doi:10.1038/nmat2297

2. C. Liu, F. Li, L.P. Ma, H.M. Cheng, Advanced materials for energy storage. Adv. Mater. 22(8), E28-E62 (2010). doi:10.1002/ adma.200903328

3. G.P. Wang, L. Zhang, J.J. Zhang, A review of electrode materials for electrochemical supercapacitors. Chem. Soc. Rev. 41(2), 797-828 (2012). doi:10.1039/C1CS15060J

4. M. Kaempgen, C.K. Chan, J. Ma, Y. Cui, G. Gruner, Printable thin film supercapacitors using single-walled carbon nanotubes. Nano Lett. 9(5), 1872-1876 (2009). doi:10.1021/nl8038579
5. Y. Huang, J.J. Liang, Y.S. Chen, An overview of the applications of graphene-based materials in supercapacitors. Small 8(12), 1805-1834 (2012). doi:10.1002/smll.201102635

6. J.P. Liu, J. Jiang, C.W. Cheng, H.X. Li, J.X. Zhang, H. Gong, H.J. Fan, $\mathrm{Co}_{3} \mathrm{O}_{4}$ nanowire $@ \mathrm{MnO}_{2}$ ultrathin nanosheet core/shell arrays: a new class of high-performance pseudocapacitive materials. Adv. Mater. 23(18), 2076-2081 (2011). doi:10.1002/adma. 201100058

7. L. Huang, D.C. Chen, Y. Ding, S. Feng, Z.L. Wang, M.L. Liu, Nickel-cobalt hydroxide nanosheets coated on $\mathrm{NiCo}_{2} \mathrm{O}_{4}$ nanowires grown on carbon fiber paper for high-performance pseudocapacitors. Nano Lett. 13(7), 3135-3139 (2013). doi:10.1021/ nl401086t

8. S.J. Peng, L.L. Li, Y.X. Hu, M. Srinivasan, F.Y. Cheng, J. Chen, S. Ramakrishna, Fabrication of spinel one-dimensional architectures by single-spinneret electrospinning for energy storage applications. ACS Nano 9(2), 1945-1954 (2015). doi:10.1021/nn506851x

9. L. Zheng, Y. Xu, D. Jin, Y. Xie, Polyaniline-intercalated molybdenum oxide nanocomposites: simultaneous synthesis and their enhanced application for supercapacitor. Chem. Asian J. 6(6), 1505-1514 (2011). doi:10.1002/asia.201000770

10. T.Y. Liu, L. Finn, M.H. Yu, H.Y. Wang, T. Zhai, X.H. Lu, Y.X. Tong, Y. Li, Polyaniline and polypyrrole pseudocapacitor electrodes with excellent cycling stability. Nano Lett. 14(5), 2522-2527 (2014). doi:10.1021/n1500255v

11. C.G. Liu, Z.N. Yu, D. Neff, A. Zhamu, B.Z. Jang, Graphenebased supercapacitor with an ultrahigh energy density. Nano Lett. 10(12), 4863-4868 (2010). doi:10.1021/nl102661q

12. X.H. Xia, J.P. Tu, Y.Q. Zhang, X.L. Wang, C.D. Gu, X.B. Zhao, H.J. Fan, High-quality metal oxide core/shell nanowire arrays on conductive substrates for electrochemical energy storage. ACS Nano 6(6), 5531-5538 (2012). doi:10.1021/nn301454q

13. K. Zhang, L.L. Zhang, X.S. Zhao, J.S. Wu, Graphene/polyaniline nanofiber composites as supercapacitor electrodes. Chem. Mater. 22(4), 1392-1401 (2010). doi:10.1021/cm902876u

14. X.H. Xia, D.L. Chao, Z.X. Fan, C. Guan, X.H. Cao, H. Zhang, H.J. Fan, A new type of porous graphite foams and their integrated composites with oxide/polymer core/shell nanowires for supercapacitors: structural design, fabrication, and full supercapacitor demonstrations. Nano Lett. 14(3), 1651-1658 (2014). doi: $10.1021 / \mathrm{nl} 5001778$

15. F.R. Jiang, W.Y. Li, R.J. Zou, Q. Liu, K.B. Xu, L. An, J.Q. Hu, MoO3/PANI coaxial heterostructure nanobelts by in situ 
polymerization for high performance supercapacitors. Nano Energy 7, 72-79 (2014). doi:10.1016/j.nanoen.2014.04.007

16. H.J. Tang, J.Y. Wang, H.J. Yin, H.J. Zhao, D. Wang, Z.Y. Tang, Growth of polypyrrole ultrathin films on $\mathrm{MoS}_{2}$ monolayers as high-performance supercapacitor electrodes. Adv. Mater. 27(6), 1117-1123 (2015). doi:10.1002/adma.201404622

17. C.Z. Yuan, H.B. Wu, Y. Xie, X.W. Lou, Mixed transition-metal oxides: design, synthesis, and energy-related applications. Angew. Chem. Int. Ed. 53(6), 1488-1504 (2014). doi:10.1002/ anie. 201303971

18. Y.H. Xiao, S.J. Liu, F. Li, A.Q. Zhang, J.H. Zhao, S.M. Fang, D.Z. Jia, 3D hierarchical $\mathrm{Co}_{3} \mathrm{O}_{4}$ twin-spheres with an urchin-like structure: large-scale synthesis, multistep-splitting growth, and electrochemical pseudocapacitors. Adv. Funct. Mater. 22(19), 4052-4059 (2012). doi:10.1002/adfm.201200519

19. R.B. Rakhi, W. Chen, D. Cha, H.N. Alshareef, Substrate dependent self-organization of mesoporous cobalt oxide nanowires with remarkable pseudocapacitance. Nano Lett. 12(5), 2559-2567 (2012). doi:10.1021/nl300779a

20. C. Feng, J.F. Zhang, Y. He, C. Zhong, W.B. Hu, L. Liu, Y.D. Deng, Sub-3 nm Co $\mathrm{O}_{4}$ nanofilms with enhanced supercapacitor properties. ACS Nano 9(2), 1730-1739 (2015). doi:10.1021/ nn506548d

21. T.Y. Ma, S. Dai, M. Jaroniec, S.Z. Qiao, Metal-organic framework derived hybrid $\mathrm{Co}_{3} \mathrm{O}_{4}$-carbon porous nanowire arrays as reversible oxygen evolution electrodes. J. Am. Chem. Soc. 136(39), 13925-13931 (2014). doi:10.1021/ja5082553

22. X.W. Wang, M.X. Li, Z. Chang, Y.F. Wang, B.W. Chen, L.X. Zhang, Y.P. Wu, Orientated $\mathrm{Co}_{3} \mathrm{O}_{4}$ nanocrystals on MWCNTs as superior battery-type positive electrode material for a hybrid capacitor. J. Electrochem. Soc. 162(10), A1966-A1971 (2015). doi: $10.1149 / 2.0041511$ jes

23. G.A. Snook, P. Kao, A.S. Best, Conducting-polymer-based supercapacitor devices and electrodes. J. Power Sources 196(1), 1-12 (2011). doi:10.1016/j.jpowsour.2010.06.084

24. C. Zhou, Y.W. Zhang, Y.Y. Li, J.P. Liu, Construction of highcapacitance 3D CoO@polypyrrole nanowire array electrode for aqueous asymmetric supercapacitor. Nano Lett. 13(5), 2078-2085 (2013). doi:10.1021/nl400378j

25. W. Hong, J.Q. Wang, Z.P. Li, S.R. Yang, Hierarchical $\mathrm{Co}_{3-}$ $\mathrm{O}_{4} @$ Au-decorated PPy core/shell nanowire arrays: an efficient integration of active materials for energy storage. J. Mater. Chem. A 3(6), 2535-2540 (2015). doi:10.1039/C4TA04707A

26. G.W. Yang, C.L. Xu, H.L. Li, Electrodeposited nickel hydroxide on nickel foam with ultrahigh capacitance. Chem. Commun. 48, 6537-6539 (2008). doi:10.1039/b815647f

27. X.H. Xia, J.P. Tu, Y.J. Mai, X.L. Wang, C.D. Gu, X.B. Zhao, Self-supported hydrothermal synthesized hollow $\mathrm{Co}_{3} \mathrm{O}_{4}$ nanowire arrays with high supercapacitor capacitance. J. Mater. Chem. 21(25), 9319-9325 (2011). doi:10.1039/c1jm10946d

28. W. Yao, H. Zhou, Y. Lu, Synthesis and property of novel $\mathrm{MnO}_{2} @$ polypyrrole coaxial nanotubes as electrode material for supercapacitors. J. Power Sources 241, 359-366 (2013). doi:10. 1016/j.jpowsour.2013.04.142

29. J. Shao, X.Y. Li, L. Zhang, Q.T. Qu, H.H. Zheng, Core-shell sulfur@polypyrrole composites as high-capacity materials for aqueous rechargeable batteries. Nanoscale 5(4), 1460-1464 (2013). doi:10.1039/c2nr33590e

30. D.C. Zhang, X. Zhang, Y. Chen, P. Yu, C.H. Wang, Y.W. Ma, Enhanced capacitance and rate capability of graphene/polypyrrole composite as electrode material for supercapacitors.
J. Power Sources 196(14), 5990-5996 (2011). doi:10.1016/j. jpowsour.2011.02.090

31. S. Bose, T. Kuila, M.E. Uddin, N.H. Kim, A.K.T. Lau, J.H. Lee, In-situ synthesis and characterization of electrically conductive polypyrrole/graphene nanocomposites. Polymer 51(25), 5921-5928 (2010). doi:10.1016/j.polymer.2010.10.014

32. M. Lenglet, J. Lopitaux, L. Terrier, P. Chartier, J. Koenig, E. Nkeng, G. Poillerat, Initial stages of cobalt oxidation by FTIR spectroscopy. J. Phys. IV 03(C9), 477-483 (1993). doi:10.1051/ jp4:1993951

33. G.D. Moon, J.B. Joo, M. Dahl, H. Jung, Y. Yin, Nitridation and layered assembly of hollow $\mathrm{TiO}_{2}$ shells for electrochemical energy storage. Adv. Funct. Mater. 24(6), 848-856 (2014). doi:10. 1002/adfm.201301718

34. L.J. Han, P.Y. Tang, L. Zhang, Hierarchical $\mathrm{Co}_{3} \mathrm{O}_{4} @ \mathrm{PPy} @ \mathrm{MnO}_{2}$ core-shell-shell nanowire arrays for enhanced electrochemical energy storage. Nano Energy 7, 42-51 (2014). doi:10.1016/j. nanoen.2014.04.014

35. B. Wang, X.Y. He, H.P. Li, Q. Liu, J. Wang, L. Yu, H.J. Yan, Z.S. Li, P. Wang, Optimizing the charge transfer process by designing $\mathrm{Co}_{3} \mathrm{O}_{4} @ \mathrm{PPy} @ \mathrm{MnO}_{2}$ ternary core-shell composite. J. Mater. Chem. A 2(32), 12968-12973 (2014). doi:10.1039/ C4TA02380C

36. W.Q. Ma, Q.Q. Shi, H.H. Nan, Q.Q. Hu, X.T. Zheng, B.Y. Geng, X.J. Zhang, Hierarchical $\mathrm{ZnO} @ \mathrm{MnO}_{2} @ P P y$ ternary core-shell nanorod arrays: an efficient integration of active materials for energy storage. RSC Adv. 5(50), 39864-39869 (2015). doi:10. 1039/C5RA06765K

37. Y. Song, X. Cai, X.X. Xu, X.X. Liu, Integration of nickel-cobalt double hydroxide nanosheets and polypyrrole films with functionalized partially exfoliated graphite for asymmetric supercapacitors with improved rate capability. J. Mater. Chem. A 3(28), 14712-14720 (2015). doi:10.1039/C5TA02810H

38. W. Tang, L.L. Liu, Y.S. Zhu, H. Sun, Y.P. Wu, K. Zhu, An aqueous rechargeable lithium battery of excellent rate capability based on a nanocomposite of $\mathrm{MoO}_{3}$ coated with PPy and $\mathrm{LiMn}_{2} \mathrm{O}_{4}$. Energy Environ. Sci. 5(5), 6909-6913 (2012). doi:10. $1039 / \mathrm{c} 2 \mathrm{ee} 21294 \mathrm{c}$

39. Q.T. Qu, Y.S. Zhu, X.W. Gao, Y.P. Wu, Core-shell structure of polypyrrole grown on $\mathrm{V}_{2} \mathrm{O}_{5}$ nanoribbon as high performance anode material for supercapacitors. Adv. Energy Mater. 2(8), 950-955 (2012). doi:10.1002/aenm.201200088

40. W. Tang, X.W. Gao, Y.S. Zhu, Y.B. Yue, Y. Shi, Y.P. Wu, K. Zhu, A hybrid of $\mathrm{V}_{2} \mathrm{O}_{5}$ nanowires and MWCNTs coated with polypyrrole as an anode material for aqueous rechargeable lithium batteries with excellent cycling performance. J. Mater. Chem. 22(38), 20143-20145 (2012). doi:10.1039/c2jm34563c

41. Y. Liu, B.H. Zhang, S.Y. Xiao, L.L. Liu, Z.B. Wen, Y.P. Wu, A nanocomposite of $\mathrm{MoO}_{3}$ coated with PPy as an anode material for aqueous sodium rechargeable batteries with excellent electrochemical performance. Electrochim. Acta 116, 512-517 (2014). doi:10.1016/j.electacta.2013.11.077

42. K. Wang, H.P. Wu, Y.N. Meng, Z.X. Wei, Conducting polymer nanowire arrays for high performance supercapacitors. Small 10(1), 14-31 (2014). doi:10.1002/smll.201301991

43. X.Y. Liu, S.J. Shi, Q.Q. Xiong, L. Li, Y.J. Zhang, H. Tang, C.D. $\mathrm{Gu}$, X.L. Wang, J.P. Tu, Hierarchical $\mathrm{NiCo}_{2} \mathrm{O}_{4} @ \mathrm{NiCo}_{2} \mathrm{O}_{4}$ core/ shell nanoflake arrays as high-performance supercapacitor materials. ACS Appl. Mater. Interfaces 5(17), 8790-8795 (2013). doi:10.1021/am402681m 